\title{
La prueba anticipada en el arbitraje
}

Marianella Ledesma Narváez

La solución de los conflictos puede hallarse bajo dos vertientes: la justicia estatal o la justicia privada. En el primer caso, privilegiamos al proceso judicial como instrumento de solución de conflictos, a diferencia de la justicia privada, en la que se recurre al manejo directo del conflicto, siempre que este pueda ser sometido a la disposición de sus titulares, como la negociación, la conciliación, la mediación y la transacción, o a la delegación de facultades a un tercero, para que sea este quien resuelva el conflicto, por medio del procedimiento arbitral. En otras palabras, todo conflicto de intereses, para ser dilucidado, permite recurrir a la jurisdicción o a la acción directa de las partes. En este último supuesto, se involucra al arbitraje, mediante el concierto de voluntades de los intervinientes, quienes van a delegar a un tercero la solución de este.

El arbitraje es catalogado como una justicia privada por las formas y modos en que los interesados deciden articularlo, desenvolverlo y respetarlo, desde el principio hasta el fin. La base del arbitraje es el contrato, expresado en el convenio que las partes celebran cuando se someten a los árbitros, todo ello sustentado en un principio constitucional que autoriza el libre ejercicio de esa voluntad contractual. ${ }^{1}$

Bajo ese contexto, señalamos que el punto de partida para el inicio del procedimiento arbitral es la designación de árbitros; sin embargo, pueden darse situaciones en las que, sin haber iniciado ninguna pretensión formal en sede arbitral, ni requerido la designación de árbitros, se busque realizar

Profesora del curso Derecho Procesal Civil de la Pontificia Universidad Católica del Perú.

1 En ese sentido, léase lo regulado en el artículo 62 de la Constitución del Estado, que dice: "ILIos conflictos derivados de la relación contractual sólo se solucionan en la vía arbitral o en la judicial, según los mecanismos de protección previstos en el contrato o contemplados en la Ley». 
— previamente - determinada actividad procesal para el futuro procedimiento arbitral.

En tales circunstancias, el sistema procesal arbitral permite que, en casos de urgencia, se mire hacia la jurisdicción para realizar dicha actividad. ${ }^{2}$ Nos referimos al caso de la medida cautelar en sede judicial, que recoge el artículo 79, Ley General de Arbitraje (en lo sucesivo LGA), mediante el cual se puede afectar el patrimonio del futuro demandado en sede arbitral para asegurar la eficacia de laudo futuro; sin embargo, hay situaciones que no buscan asegurar algún patrimonio para una futura ejecución forzada del laudo o mantener o cambiar una situación de hecho controvertida que será materia de una futura discusión arbitral, sino que buscan asegurar algún medio de prueba para el futuro procedimiento arbitral. Véase el caso del siniestro en un almacén provocado por un desperfecto eléctrico en las instalaciones del local y por causa no imputable al encargado de la custodia de este. Para la futura indemnización que se reclame, se hace necesario recoger todas las «fuentes de prueba» que serán canalizadas, en su momento, por los diferentes medios de prueba en el procedimiento arbitral; sin embargo, hasta que se inicie el procedimiento arbitral, se hace necesario poner a buen recaudo los elementos que puedan llevar a configurar alguna responsabilidad civil o liberar de esta. En el caso citado, se hace imperativo practicar la pericia, para que, recogiendo las huellas o vestigios de la escena del siniestro, se determinen las causas de este.

La LGA no regula el aseguramiento de la prueba por la jurisdicción, previo al procedimiento arbitral. Solo recoge la posibilidad de la medida cautelar previa; sin embargo, frente a ese vacío normativo, es necesario construir alguna respuesta al respecto.

\section{Análisis del tema propuesto a discusión}

1.

El arbitraje es una institución de orígenes remotos. Según Gómez de Liaño, ${ }^{3}$ es posiblemente la forma de solución de conflictos que apareció primero

La institución del arbitraje, aun configurándose como alternativa a la jurisdicción, necesita de la intervención de esta, sea a instancia de parte o de los árbitros, para el inicio del procedimiento arbitral o para las diversas fases del mismo, como sucede con la impugnación y ejecución de laudos, la medida cautelar, la prueba delegada y la designación de peritos.

Gómez de liaño Gonzáles, Fernando y Agustín Pérez-Cruz Martín. Derecho Procesal Civil. T. 2. Oviedo: Fórum, 2001, p. 901. 
en el tiempo, antes que se organizare cualquier órgano jurisdiccional; este aparece legitimado por la propia voluntad de los interesados, de manera que la misma facultad que cualquier persona tiene para decidir, disponer y transigir sobre cuestiones que en el campo del derecho están a su libre disposición puede diferirla a un tercero.

En un sentido amplio podemos decir que el arbitraje es un medio de solución de conflictos sociales mediante la intervención de un tercero, llamado árbitro, a cuya decisión se someten las partes sobre materias que libremente pueden disponer. Es definido, según Diez-Picazo, ${ }^{4}$ como «aquella institución consistente en que dos o más personas pactan entre sí que un tercero resuelva un litigio ya surgido o que pueda surgir entre ellas, excluyendo que los tribunales conozcan del mismo». Gómez Colomer ${ }^{5}$ señala que

[...] es una institución jurídica heterocompositiva, en virtud de la cual una tercera persona, objetiva e imparcial, nombrada por las partes mediando convenio, resuelve en base a una potestad específica el conflicto intersubjetivo de intereses jurídico, en caso de ser la materia susceptible de disposición por las personas afectadas por la discrepancia.

De lo expuesto podemos señalar como características básicas del arbitraje las siguientes: constituye un derecho —en general— de los particulares someter la decisión de cuestiones controvertidas al arbitraje; opera sobre materias respecto de las cuales las partes pueden libremente disponer; requiere de un convenio arbitral que permita, en forma expresa y legitima, la intervención del árbitro; y comprende un procedimiento sencillo y poco formalista que concluye con el laudo arbitral que decide el conflicto.

2.

Antes que se inicie formalmente el procedimiento arbitral, pueden acaecer situaciones que lleven a la necesidad de mirar a la jurisdicción para acopiar y resguardar las fuentes de prueba, para lo cual recurrimos a diversas actuaciones judiciales destinadas a «facilitar» no solo la vida del futuro proceso ulterior, sino el desarrollo y la eficacia de este.

La «facilitación procesal» es un concepto puramente doctrinal y no legal. Comprende — según Guasp - al conjunto de procesos orientados a

DIEZ-PICAZO JIMÉNEZ, Ignacio. Derecho Procesal Civil. Madrid: Centro de Estudios Ramón Areces, 2000, p. 574.

GÓmez Colomer, Juan. Derecho Jurisdiccional. Vol. II. Barcelona: Bosch, 1995, p. 843. 
facilitar otro proceso principal, con el que aparecen relacionados. Estos procedimientos especiales orientados a facilitar la vida del proceso principal son catalogados por Palacio ${ }^{6}$ como diligencias preliminares y se agrupan, atendiendo a la finalidad que persiguen, en dos categorías: diligencias preparatorias y diligencias conservadoras de prueba.

Según Palacio, ${ }^{7}$ las diligencias preparatorias tienen por objeto asegurar a las partes la idoneidad y precisión de sus alegaciones, lo que les permite el acceso a elementos de juicio susceptibles de delimitar, con la mayor exactitud posible, los elementos de su futura pretensión u oposición o la obtención de medidas que faciliten los procedimientos ulteriores. En cambio, la diligencia conservatoria de prueba, o prueba anticipada, tiene por objeto la producción anticipada de ciertas medidas probatorias frente al riesgo de que resulte imposible o sumamente dificultoso hacerlo durante el período procesal correspondiente. El Código Procesal Civil las acoge (diligencia preparatoria y prueba anticipada) bajo la nomenclatura de esta última, como veremos a continuación; sin embargo, sostenemos que solo la inspección judicial, los testigos y la pericia pueden ser tratados realmente como pruebas anticipadas, situación que no puede ser extensiva para el reconocimiento, la absolución de posiciones ni para la exhibición, por estar diseñadas como diligencias preparatorias.

3.

El tema propuesto a discusión, como es la prueba anticipada, es abordado por Guasp bajo la denominación de facilitador procesal. Mediante estos facilitadotes, se busca remover los obstáculos que puedan presentarse respecto a la eficacia del futuro proceso.

La prueba anticipada es un mecanismo destinado a contribuir al adecuado desarrollo de la actividad probatoria. Tiene un propósito garantista porque busca evitar que determinados medios probatorios, al no actuarse oportunamente, sean afectados y se frustre la posibilidad de que sean utilizados en un proceso posterior.

Esta finalidad de asegurar y conservar medios de prueba lleva a confundirlo con la medida cautelar; sin embargo, hay dos grandes argumentos para excluirla.

PalACIO, Lino. Derecho Procesal Civil. 5. reimpresión. T.VI. Buenos Aires: Abeledo Perrot, s./f., p. 11

Ib., loc. cit.. 
a) La prueba anticipada no participa de las características de la medida cautelar, como lo provisional y mutable de la medida. Lo provisional implica que la medida subsiste mientras duren las circunstancias que la determinaron; y es mutable porque el juez, para evitar perjuicios innecesarios, puede disponer de medida cautelar diferente de la solicitada. Estas características no son aplicables a la prueba anticipada porque, producida en cualquier etapa, se incorpora al proceso en definitiva y el juez no puede dejar de valorarla aunque perjudique a la parte que la produjo. Esa valoración opera al momento de dictar sentencia definitiva.

b) La medida cautelar se decreta inaudita pars; en cambio, la prueba anticipada se practica con citación de la parte contraria, salvo que resulte imposible por razón de urgencia (véase art. 287 del Código Procesal Civil).

De lo expresado líneas arriba, podemos señalar que las pruebas producidas con anterioridad a la interposición de la demanda poseen aptitud para incorporarse al proceso con carácter definitivo y ser valoradas en pie de igualdad con aquellas cuyo cumplimiento se verifique durante dicho período, razón por la cual carecen de los atributos de provisionalidad y modificabilidad que son propios de las medidas cautelares.

4.

El poder jurídico que tiene toda persona de recurrir a la jurisdicción para buscar tutela no se materializa por medio de la demanda, sino que, sin necesidad de ella, se puede ejercer el derecho de acción, mediante otros mecanismos como la prueba anticipada. Técnicamente no es una demanda, pero se acude al órgano judicial en busca de tutela; se materializa, de esta manera, el derecho de acción. Aquí se da inicio a una instancia, mas no al proceso, porque se acude al órgano judicial sin demanda, sin pretender iniciar un proceso inmediato. ${ }^{8}$

8 En este sentido, véase los siguientes pronunciamientos judiciales:

"La prueba anticipada consiste en la actuación de medio probatorio antes del inicio del proceso, correspondiéndole el trámite del proceso no contencioso; siendo esto así, es obvio que no contiene pretensión específica de la parte solicitante y tampoco se declara derecho alguno para esta a la culminación del trámite» (exp. 706-98-Lima, 07 de julio de 1998). Ejecutoria citada en Pioner de Jurisprudencia, Boletín Mensual, año 1, n. ${ }^{\circ}$ 10, abril, 2004, p. 27, Lima.

"La actuación anticipada de una determinada prueba tiene por objeto, por sí misma o como parte del caudal probatorio, preparar los fundamentos que han de sustentar la causa petendi de la futura pretensión a interponerse en el proceso correspondiente, por lo que en dicha actuación anticipada no se resolverá en sí el conflicto de intereses, sino en aquél proceso en el que se discuta el fondo de la litis, mediante sentencia o auto que 


\subsection{La oportunidad para recurrir}

Un aspecto importante que se debe tener en cuenta en la prueba anticipada es la oportunidad a recurrir. Tomando como referencia el artículo 284 del Código Procesal Civil, encontramos que «toda persona legitimada puede solicitar la actuación de medio probatorio antes del inicio de un proceso".

Se justifica esta intervención porque el inicio del procedimiento arbitral puede tornarse conflictivo, lo que obliga a recurrir a la jurisdicción para la designación de árbitros (véase el caso regulado en el art. 23 y 24 LGA); mientras tanto, las fuentes de prueba requieren ser cauteladas para el futuro procedimiento arbitral, motivo que amerita tomar las medidas urgentes necesarias para cautelarla.

Bajo una interpretación del artículo 284 del Código Procesal Civil, se podría permitir la práctica de la prueba anticipada hasta antes del inicio de un procedimiento arbitral. Solo opera para el acopio de pruebas antes del inicio de este; luego, ya no podrá invocarse la intervención de la jurisdicción, salvo en caso de que el Tribunal Arbitral disponga el acopio de la prueba según el artículo 40 LGA. Sin embargo, nos atrevemos a proponer, de manera excepcional, que, cuando se haya iniciado el procedimiento arbitral y concurran situaciones que entorpezcan la integridad de estas o sobrevenga el temor de que la producción de las pruebas pudiera resultar imposible o muy dificultosa de practicar en el período de prueba fijado para el procedimiento arbitral, motivaría que se altere el diseño procesal trazado por las partes, para actuarlas por la urgencia del caso, pues podrían desaparecer. ${ }^{9}$ Como ya se ha señalado, la prueba anticipada debe entenderse como un procedimiento de excepción y no una norma de aplicación general. Lo excepcional radica en que deban mediar razones que justifiquen la urgencia. ${ }^{10}$ Bajo ese contexto, léase el siguiente pronunciamiento:

en revisión ponga fin al proceso» (casación 1261-99-Lima, 30 de junio de 1999, sala civil permanente de la Corte Suprema). Publicada en Diálogos con la Jurisprudencia, año 9, n. ${ }^{\circ}$ 67, abril, 2004, p. 236, Lima.

$9 \quad$ No hay impedimento para que la actividad de los árbitros y la de los órganos jurisdiccionales se interrelacionen. En primer lugar, los órganos jurisdiccionales colaboran para lograr la efectividad del arbitraje; por citar, a falta de acuerdo respecto de la designación de árbitros, puede instarse a la formalización judicial; las dificultades que la carencia del imperium de los árbitros podían originar en el desarrollo del procedimiento arbitral se suplen acudiendo a los órganos jurisdiccionales, para adoptar medidas tendentes a asegurar la plena efectividad del laudo o para proceder a la ejecución forzosa. En segundo lugar, existe un control sobre el correcto desarrollo del arbitraje y el cumplimiento de las garantías procedimentales establecidas legal o convencionalmente por medio del llamado recurso de anulación.

10 "La motivación para la actuación probatoria antes del inicio del proceso, tiene que estar referida a situaciones de urgencia, de modificación u otras análogas, que exigen una 
La actuación anticipada de una determinada prueba tiene por objeto, por sí misma o como parte del caudal probatorio, preparar los fundamentos que han de sustentar la causa petendi de la futura pretensión a interponerse en el proceso correspondiente, por lo que en dicha actuación anticipada no se resolverá en sí el conflicto de intereses, sino en aquél proceso en el que se discuta el fondo de la litis, mediante sentencia o auto que en revisión ponga fin al proceso. ${ }^{11}$

En ese mismo sentido, aparecen los siguientes fallos:

[L]a motivación para la actuación probatoria antes del inicio del proceso, tiene que estar referida a situaciones de urgencia, de modificación u otras análogas, que exigen una intervención pronta del órgano jurisdiccional a efectos que la prueba no pierda su utilidad y eficacia. ${ }^{12}$

Siendo que excepcionalmente la ley prevé la posibilidad de actuar los medios probatorios antes del proceso a instaurarse, se exige que la parte explicite la justificación de dicha actuación anticipada, significando que ello podría ser que los hechos a constatarse en una inspección judicial estén en la situación de inminente desaparición y no sería razonable esperar su actuación dentro del proceso a instaurar. ${ }^{13}$

\subsection{La admisibilidad y procedencia}

La prueba anticipada es una expresión de las diligencias preliminares, que tiene por objeto la producción de ciertas medidas probatorias frente al riesgo

intervención pronta del órgano jurisdiccional a efectos que la prueba no pierda su utilidad y eficacia» (exp 699-98, resolución del 09 de julio de 1998, sala civil de Lima, procesos sumarísimos y no contenciosos). Publicada en Diálogos con la Jurisprudencia, año 9, n. ${ }^{\circ}$ 67, abril, 2004, p. 238, Lima.

"Siendo que excepcionalmente la ley prevé la posibilidad de actuar los medios probatorios antes del proceso a instaurarse, se exige que la parte explicite la justificación de dicha actuación anticipada, significando que ello podría ser que los hechos a constatarse en una inspección judicial estén en la situación de inminente desaparición y no sería razonable esperar su actuación dentro del proceso a instaurar» (exp. 46796-99, resolución del 28 de marzo de 2000, sala civil de Lima, procesos sumarísimos y no contenciosos). Publicada en Diálogos con la Jurisprudencia, año 9, n. ${ }^{\circ} 67$, abril, 2004, p. 238, Lima.

11 Casación 1261-99-Lima, 30 de junio de 1999, sala civil permanente de la Corte Suprema, publicada en Diálogos con la Jurisprudencia, año 9, n. ${ }^{\circ}$ 67, abril, 2004, p. 236, Lima.

12 Exp. 699-98, resolución del 09 de julio 1998, sala civil de Lima, procesos sumarísimos y no contenciosos, publicada en Diálogos con la Jurisprudencia, año 9, n. ${ }^{\circ} 67$, abril, 2004, p. 238, Lima.

13 Exp. 46796-99, resolución del 28 de marzo de 2000, sala civil de Lima, procesos sumarísimos y no contenciosos, publicada en Diálogos con la Jurisprudencia, año 9, $n .^{\circ} 67$, abril, 2004, p. 238, Lima. 
que de resulte imposible o sumamente dificultoso hacerlo antes del proceso o durante el período procesal correspondiente. Frente a ello, surgen algunas interrogantes sobre la admisibilidad y procedencia, como las que a continuación citamos:

1. No existe regulación específica sobre el juez competente para la prueba anticipada, cuyo futuro proceso será el procedimiento arbitral; sin embargo, consideramos que para su admisibilidad y procedencia se recurra a las reglas del Código Procesal Civil, por la aplicación supletoria que recoge la primera disposición final del citado Código, que dice: «Las disposiciones de este Código se aplican supletoriamente a los demás ordenamientos procesales, siempre que sean compatibles con su naturaleza».

Aplicando las reglas del proceso judicial, esta competencia será fijada en atención al grado, como señala el artículo 33 del Código Procesal Civil. ${ }^{14}$ Frente a esta regulación, el artículo 297 del mismo Código, además, ha hecho extensiva la competencia a supuestos de cuantía y territorio del futuro proceso por conocer como criterios para delimitar la competencia del juez en la prueba anticipada. Por otro lado, es importante destacar que la producción de pruebas anticipadas no implica renuncia al arbitraje pactado, en igual forma que la medida cautelar en sede judicial antes de iniciado el procedimiento arbitral (véase art. 79 LGA).

2. Corresponde al solicitante la carga de suministrar los hechos relativos al tipo de pretensión de que será objeto del futuro proceso.

Al margen de enunciar la clase de pretensión que ha de configurar el objeto del proceso, el peticionario debe expresar los motivos en que aquella se funda. Su ausencia impediría al órgano judicial efectuar una adecuada valoración acerca de la necesidad de practicar dicha prueba. En este sentido, compartimos la opinión de Condorelli ${ }^{15}$ cuando señala que

[...] las diligencias preliminares no deben ser permitidas mas allá de lo estrictamente necesario, porque de otra manera podrían quedar comprometidos los principios de igualdad y lealtad al procurarse una de las partes informaciones por vía jurisdiccional sin la plenitud del contradictorio, máxime cuando no se ha acreditado que la información requerida resulte imperiosa a efectos de una eventual modificación o ampliación de la demanda.

${ }^{14}$ Artículo 33.- Medida cautelar y prueba anticipada.

Es competente para dictar medida cautelar antes de la iniciación del proceso y para la actuación de la prueba anticipada, el Juez competente por razón de grado para conocer la demanda próxima a interponerse.

15 Condorelli, Epifanio. Del abuso y la mala fe dentro del proceso. Buenos Aires: Abeledo-Perrot, 1986, p. 118. 
3. En relación con la legitimidad activa, en el pedido de la prueba anticipa$\mathrm{da}$, esta le corresponde tanto al futuro actor como al futuro demandado. Esta posición se sustenta en el principio de igualdad de las partes que rige al proceso; además, esta postura es válida porque negar al futuro demandado la posibilidad de preparar su eventual medio probatorio para oponer a la futura pretensión — aun en sede arbitral — puede traducirse en una frustración de la garantía a la defensa. En este sentido, léase lo señalado en el artículo 284 del Código Procesal Civil: "Toda persona legitimada puede solicitar la actuación de medio probatorio, antes del inicio del proceso».

4. La prueba anticipada es admisible frente a la eventual interposición de una pretensión de cognición, para lo cual, conforme refiere el artículo 284 del Código Procesal Civil, «el juez solo admitirá la solicitud si se cumple con expresar la pretensión genérica que va a reclamar y la razón que justifica su actuación anticipada».

En esa línea, uno de los problemas que presenta el Código es la ausencia de mecanismos de sanción y control, en caso de incumplimiento, respecto de quien solicita la prueba anticipada, promueve la actividad de la jurisdicción y luego no inicia el procedimiento arbitral que alegó.

Como apreciamos en el caso de la medida cautelar fuera de proceso, si no es seguida con la interposición de la demanda dentro del plazo que fija la ley, no ofrece mayor dificultad porque opera la caducidad automática de la medida. ${ }^{16}$ Este criterio, de fijar un plazo especial para interponer la demanda luego de haber ejecutado la medida cautelar, merece ser extensiva también al aseguramiento de pruebas, pero atribuyéndole un plazo especial.

En relación con el plazo, hay un sector de la doctrina que considera aplicable el plazo legal del supuesto de la caducidad de la instancia (lo que conocemos según el Código Procesal como abandono) en caso de que no se interponga la demanda dentro de los cuatro meses de ejecutada la prueba anticipada. Por supuesto, la caducidad de la prueba anticipada no se produciría en forma automática como opera en caso del artículo 636 del Código Procesal Civil, medida cautelar fuera del proceso, sino que estaría supeditada al pedido que en ese sentido formule la parte afectada con la medida. Desde la óptica de Condorelli, ${ }^{17}$ «se justifica el

16 Véase Artículo 636.- Medida fuera de proceso.

Ejecutada la medida antes de iniciado el proceso principal, el beneficiario debe interponer su demanda ante el mismo Juez, dentro de los diez días posteriores a dicho acto. Si no se interpone la demanda oportunamente, o ésta es rechazada liminarmente, la medida caduca de pleno derecho. Dispuesta la admisión de la demanda por revocatoria del superior, la medida cautelar requiere nueva tramitación.

17 CONDOREllı, Epifanio. Op. cit., p. 116. 
mentado plazo de caducidad, dado que tiene que existir un momento final que concluya con una situación de incertidumbre; no es posible que se demore, por el proponente de la diligencia preliminar sine die la iniciación del proceso de conocimiento».

5. En cuanto al procedimiento de la prueba anticipada, decimos que las pruebas producidas antes del procedimiento arbitral o fuera del mismo, con citación personal de la parte contra quien se la intenta hacer valer, pueden tener el mismo valor que las producidas al interior del principal. Cuando se trata del informe producido sin orden judicial, este no configuraría prueba pericial e, incluso ratificado, devendría, en el mejor de los supuestos, en prueba documental.

Se trata de una concreta aplicación del principio de contradicción en la prueba, por lo que esta, para ser válida, debe haber sido producida con intervención de la parte contraria.

En igual sentido, se ha resuelto que la testimonial contenida en actas notariales no tiene jerarquía de prueba, pues, para que ello ocurra, debió haber mediado la intervención de un órgano jurisdiccional, lo que en definitiva otorga al proceso la garantía del contradictorio.

La preconstitución unilateral de prueba - por la propia parte a su favorno constituiría prueba en el sentido técnico, por lo que carecería de toda eficacia en tal sentido. Por otro lado, la prueba anticipada autoriza solicitar anticipadamente a los que sean o vayan a ser parte en un proceso y tuvieren motivos justificados para temer que la producción de sus pruebas pudiera resultar imposible o dificultosa la declaración de un testigo de muy avanzada edad o que esté gravemente enfermo o próximo a ausentarse del país, o la pericia, si hay riesgo de que el transcurso del tiempo u otra circunstancia alteren el estado o situación de personas, lugares, bienes o documentos. ${ }^{18}$ Si el juez admite, se practica con citación de la futura parte contraria, salvo que resultare imposible por razones de urgencia. En este caso, el juez puede ordenar — a pedido de parte- la actuación del medio probatorio, sin citación, por resolución motivada y sustentada en razones de garantía y seguridad; toma en cuenta, para ello, el petitorio de la futura demanda. ${ }^{19}$ Lo desarrollado líneas arriba nos permite sostener lo siguiente:

18 Véanse artículos 290 y 291 del Código Procesal Civil.

19 Sobre el particular, véase la siguiente ejecutoria:

"La peticionante solicita que la prueba anticipada se realice sin citación de la emplazada, Corporación San Francisco SA y P\&VC Consultores Sociedad Anónima, sin embargo, dicho pedido no se encuentra sustentado en razones de garantía y seguridad conforme taxativamente lo señala el segundo párrafo del art. 287 CPC. El juez podrá ordenar la actuación del medio probatorio sin citación de la persona a quien se pretende emplazar, por resolución debidamente motiva, mandato que no ha sido cumplido por el juez al 
- La prueba anticipada se orienta a cautelar las fuentes de prueba para el futuro medio de prueba.

- La urgencia justifica su actuación con antelación al proceso; ello significa que tiene un carácter excepcional, pues lo ordinario de la actuación probatoria debe darse en el interior del proceso.

- Nada impide que, pese ha haberse celebrado el convenio arbitral para someter al arbitraje los conflictos, se recurra a la jurisdicción para el acopio de una fuente de prueba antes del inicio del procedimiento arbitral.

- Si bien el convenio arbitral tiene un sustento en la autonomía de la voluntad, es factible que opere a futuro la renuncia tácita al arbitraje al someterse a la jurisdicción sin interponer la excepción de convenio arbitral.

- La LGA regula la medida cautelar en sede judicial, condicionada a que, luego de su ejecución, se inicie el procedimiento arbitral; sin embargo, al no existir regulación legal sobre el acopio y actuación de pruebas con antelación al arbitraje, consideramos que ella perfectamente puede operar recurriendo al Código Procesal Civil para la integración de la norma.

6. Otro aspecto que merece especial comentario es la posibilidad de recurrir a la jurisdicción para obtener un título ejecutivo (mediante de la llamada prueba anticipada), a pesar de haberse pactado el convenio arbitral. Como se ha señalado, ${ }^{20}$ bajo la denominación de prueba anticipada se procuran los requisitos de un proceso principal ulterior: aquí el proceso principal depende, para su válido nacimiento, de la existencia de un título, es decir, de un fundamento objetivo específico, sin el cual no puede admitirse su tramitación. También se puede recurrir a la jurisdicción para facilitar el desarrollo del futuro proceso, esto es, cuando la vida normal de un proceso principal depende del planteamiento y solución de cuestiones relacionadas con él. Aquí la finalidad es verificar las aclaraciones correspondientes, como es el caso de la exhibición en prueba anticipada. Según Guasp, ${ }^{21}$ «la aclaración procesal puede referirse a

disponer que se actúe la prueba sin emplazarse a la contraria; por cuanto del contexto de la resolución admisoria no se advierten los fundamentos o motivos de las razones de garantía y seguridad indicadas en ella, infringiendo de este modo el inciso 3 del art. 122 del CPC» (exp. 2226-99, resolución del 21 de marzo de 2000) Publicada en Diálogos con la Jurisprudencia, año 9, n. ${ }^{\circ} 67$, abril, 2004, p. 237, Lima.

20 Véase supra 2.

21 GUASP, Jaime. Derecho Procesal Civil. 3. ${ }^{a}$ ed. T. II. Madrid: Instituto de Estudios Políticos, 1968, p. 665. 
cuestiones que surgen durante la pendencia de un proceso principal, cuando se quiere resolver dichas cuestiones mediante una tramitación autónoma, que deje, por lo menos en principio, más expedito el cauce del proceso al que se trata de facilitar».

Bajo esas circunstancias, nos preguntamos si es procedente recurrir a la jurisdicción para buscar el reconocimiento o la absolución de posiciones para un futuro procedimiento arbitral que se debe iniciar o, en todo caso, buscar la exhibición con el mismo fin. Sobre el particular, aparece la ejecutoria emitida por la sala civil de Lima, ${ }^{22}$ que declara improcedente el pedido de exhibición y absolución de posiciones en prueba anticipada. Esa decisión se justifica en que las partes han pactado someterse a arbitraje y, si bien en aplicación del artículo 284 del Código Procesal Civil se señala que la pretensión genérica por interponer será la de un proceso ejecutivo, dicho ingreso a la jurisdicción resulta improcedente por la competencia pactada por las partes.

Los argumentos que acoge la citada ejecutoria superior no dejan de ser ciertos; sin embargo, debe tenerse en cuenta que, a pesar de haberse pactado el convenio arbitral, cabe la renuncia tácita a este cuando se decide recurrir a la jurisdicción y no se interpone la excepción de convenio arbitral oportunamente (véase inciso 13 del art. 446 del Código Procesal Civil) o, como señala el artículo 15 LGA, «las partes pueden renunciar al arbitraje mediante convenio expreso. Se entiende que existe renuncia tácita cuando se hubiera interpuesto demanda por una de las partes y el demandado no invoca la excepción arbitral dentro de los plazos previstos para cada proceso». Bajo ese contexto, consideramos que sí cabría recurrir a la jurisdicción para celebrar en prueba anticipada el reconocimiento o la absolución de posiciones que constituyen títulos ejecutivos, los mismos que perfectamente podrían ser iniciados en sede judicial, a pesar del convenio arbitral, y continuar en él, siempre que prospere la renuncia tácita al arbitraje.

Apréciese que dentro de los medios probatorios típicos que acoge el Código Procesal Civil, solo la inspección judicial, los testigos y la pericia se pueden considerar como pruebas anticipadas, situación que no es extensiva para el reconocimiento y la absolución de posiciones por responder estos a procesos especiales que procuran crear títulos para un proceso principal ulterior, como es el caso de los títulos ejecutivos provenientes de la absolución de posiciones y el reconocimiento. ${ }^{23}$ En tal

22 Ejecutoria recaída en el expediente 36249-98, sala de procesos sumarísimos, 30 de septiembre de 1999, publicada en LEDESMA, Marianella. Jurisprudencia actual. T. 5. Lima: Gaceta Jurídica, 2003, p. 608.

23 Artículo 294.- Absolución de posiciones.- 
sentido, hay que fijarse en que los apercibimientos recogidos en el artículo 296 del Código Procesal Civil no hacen referencia a la inspección judicial, testigos ni peritos. Como señala el inciso 3) y 4) del artículo 693 de dicho Código, se puede promover proceso ejecutivo en mérito de los siguientes títulos: "prueba anticipada que contiene un documento privado reconocido" (véase inciso 3); "prueba anticipada que contiene una absolución de posiciones, expresa o ficta» (véase inciso 4).

Este proceso, más que de creación, es de reconocimiento, porque el título en principio existe y lo único que se hace es integrarlo o complementarlo con actividades especiales de las que depende su fuerza ejecutiva. El documento privado solo tiene fuerza ejecutiva si ha sido reconocido ${ }^{24}$ por consiguiente, hace falta una diligencia preparatoria con el objeto de lograr la fuerza ejecutiva de tal documento privado. Por otro lado, el proceso de creación en la absolución de posiciones como título sumario comienza cuando, para preparar la ejecución, se pide que el deudor confiese bajo juramento la certeza de la deuda. Esto podría llevar quizá a afirmar — como señala Guasp— ${ }^{25}$ que

[...] las diligencias preparatorias no son un proceso especial, sino simples medidas accesorias del proceso principal al que han de servir, sin embargo, esta conclusión, contradiría el mecanismo real, y no meramente aparente, de las diligencias preparatorias, las cuales en realidad, tienen una existencia independiente del proceso ulterior, puesto que no solo lo preceden, sino que incluso pueden terminar sin que el juicio ejecutivo, más tarde, venga a ser promovido.

7. Por otro lado, la exhibición es una diligencia que busca aclarar las cuestiones que pueden surgir antes del nacimiento del arbitraje. Tiene una finalidad esencial y específica, que es la de obtener la necesaria y adecuada información sobre determinadas cuestiones relacionadas con el objeto del correcto del proceso ulterior. Como señala García, ${ }^{26}$ «son aquellas actividades que previas al proceso se solicitan al órgano jurisdiccional con la finalidad de preparar el mismo».

Puede solicitarse que la presunta contraparte absuelva posiciones sobre hechos que han de ser materia de un futuro proceso.

Artículo 292.- Reconocimiento de documentos privados.-

Cualquier interesado en el contenido o efectos de un documento, puede solicitar que su otorgante o sus herederos lo reconozcan.

24 Véase inciso 3, artículo 693 del Código Procesal Civil.

25 GUASP, Jaime. Op. cit., p. 660.

26 GarCIA VILA, Mónica. "Diligencias preliminares y la negativa a su práctica». Revista Peruana de Derecho Procesal, t.VI, 2003, p. 149, Lima. 
Estas diligencias preliminares operan bajo la exhibición solo para aquellas taxativamente señaladas en el artículo 293 del Código Procesal Civil ${ }^{27}$ sin embargo, es preciso establecer que todo proceso puede prepararse cuando se persiguen finalidades que afectan a los sujetos, al objeto o al título que pueden jugar en el proceso ulterior no solo recurriendo exclusivamente a la exhibición sino también a la absolución de posiciones. La preparación del futuro proceso va encaminada a la averiguación de determinados datos que son necesarios para identificar al sujeto pasivo del futuro proceso. Con esta información preliminar, se puede evitar la realización de un proceso inútil

\section{Conclusión}

Frente a la disyuntiva planteada con relación a si resulta procedente practicar en sede judicial la prueba anticipada para conservar alguna fuente de prueba, para crear un título ejecutivo o para aclarar una situación para una futura demanda, sostenemos que sí es factible realizarlo en sede judicial a pesar de haberse pactado el convenio arbitral.

El hecho de que se recurra a la jurisdicción para la prueba anticipada existiendo convenio arbitral no implica renuncia al arbitraje, pues este recién operará en el supuesto de que se someta el conflicto a discusión en sede judicial y las partes no interpongan la excepción correspondiente. Lo que se busca con este tipo de licencias para el acopio y actuación de la prueba es no privar de tutela judicial a quien requiere conservar alguna fuente de prueba ante la ausencia temporal del procedimiento arbitral. Hay un criterio de urgencia que justifica ese tipo de tutela, sin que ello implique que tenga la connotación de una medida cautelar.

Por último, debemos tener en cuenta que el arbitraje está sustentado en el ejercicio de la autonomía privada de partes; en tal sentido, perfectamente puede operar la renuncia tácita al arbitraje al someter su conflicto a sede judicial sin interponer la excepción de convenio arbitral oportunamente. En tal sentido, resulta coherente que se recurra a la tutela de la jurisdicción para la prueba anticipada.

27 Artículo 293.- Exhibición.-

Cuando una persona requiera del esclarecimiento previo de una relación o situación jurídica, puede pedir la exhibición de:

1. El testamento del causante por parte de quien se considere sucesor;

2. Los documentos referentes al bien relacionado con el futuro proceso;

3. Los estados de cuentas, libros y demás documentos relativos a negocios o bienes en que directamente tiene parte el solicitante; y

4. Otros bienes muebles materia de un futuro proceso. 